\title{
Statistical Modeling on Blindness and Visual Impairment Data
}

\author{
Shankar Prasad Khanal ${ }^{1 *}$, Krishna Prasad Acharya ${ }^{2}$, Pravat Uprety ${ }^{1}$, Santosh Kumar Shah ${ }^{1}$ \\ ${ }^{1}$ Central Department of Statistics, Tribhuvan University, Nepal \\ ${ }^{2}$ Shanker Dev Campus, Tribhuvan University, Nepal \\ *E-mail: shankar_cds@yahoo.com
}

\begin{abstract}
Blindness and visual impairment remain leading causes of disability in the world, and also considered one of the major eye problems in Nepal. This study was planned to identify the significant risk factors of visual impairment and blindness based on hospital data. The analysis is based on 2000 patients' information with age $\geq 40$ years retrospectively. Logistic regression model is used to identify the risk factors of visual impairment. Altogether 710(36\%) subjects were having visually impaired (low vision) and very few 29(1.45\%) were having blindness. The proportion of having visual impairment and blindness each is found higher in the females as compared to males $(p=0.026)$. The prevalence of having visual impairment in the age group of 40 - 49 years with 95\% C.I. is $13.11 \%(10.76 \%-15.75 \%)$ and it reaches to very high $(89.00 \% ; 84.89 \%-92.30 \%)$ in the patients having age 70 years or more. The odds of having visual impairment is 8 times more $(\mathrm{OR}=7.99,95 \%$ C.I.: 3.99 - 15.98, $\mathrm{p}<0.001)$ in 60 - 69 age group of people as compared with those of 40 - 49 age group based on visual acuity after correction. Risk of developing visual impairment is found to be increasing exponentially with increasing age.
\end{abstract}

Key words: Visual impairment, blindness, odds ratio, exponentially

\section{INTRODUCTION}

Blindness is frequently used to describe severe visual impairment. Visual impairment or vision impairment(VI) is vision loss (of a person) to such a degree as to qualify as an additional support need through a significant limitation of visual capability resulting from either disease, trauma, or congenital or degenerative conditions that cannot be corrected by conventional means, such as refractive correction, medication, or surgery. The International Classification of Diseases $10^{\text {th }}$ edition (ICD10) defines visual impairment as visual acuity of less than $6 / 18(20 / 60,0.3)$ in the better eye with the best correction (WHO, 1992). Visual impairment has been categorized to blindness and low vision. A visual acuity of less than $3 / 60(20 / 400,0.05)$ with best correction or a visual field less than $10^{\circ}$ from fixation in the better eye has been considered blindness. Low vision has been defined as a best corrected visual acuity of less than $6 / 18$ $(20 / 60,0.3)$ but not less than $3 / 60(20 / 400,0.05)$ in the better eye. Presenting visual acuity has also been used to describe visual impairment within the study sample.

Blindness and severe visual impairment remain leading causes of disability in the world. Globally, in 2002, more than 161 million people were visually impaired, of whom 124 million people had low vision and 37 million were blind (WHO, 2004). However, refractive error as a cause of visual impairment was not included, which implies that the actual global magnitude of visual impairment is greater. Worldwide for each blind person, an average of 3.4 people has low vision, with country and regional variation ranging from 2.4 to 5.5. Visual impairment is unequally distributed across age groups. More than $82 \%$ of all people who are blind are 50 years of age and older, although they represent only $19 \%$ of the world's population. Due to the expected number of years lived in blindness (blind years), childhood blindness remains a significant problem, with an estimated 1.4 million blind children below age 15. Available studies consistently indicate that in every region of the world, and at all ages, females have a significantly higher risk of being visually impaired than males. Geographically, visual impairment is not distributed uniformly throughout the world. More than $90 \%$ of the worlds visually impaired live in developing countries ("All countries", n.d.).

According to WHO estimates, the most common cause of blindness around the world in 2002 are cataracts (47.9\%), glaucoma (12.3\%), age-related macular degeneration $(8.7 \%)$, corneal opacity $(5.1 \%)$, diabetic retinopathy (4.8\%), childhood blindness (3.9\%), trachoma (3.6\%), onchocerciasis $(0.8 \%)$ etc ("Blindness," n. d.).

The WHO estimated that the prevalence of blindness amongst people with age $>50$ years in South East Asia to be $3.4 \%$. These are crude estimates from population based studies in India, Bangladesh and Pakistan (Pascolini et al. 2004). The survey namely "Nepal Blindness Survey" conducted in 1981 summarized that the overall prevalence of blindness (visual acuity $<3 / 60$ in the better eye) was $0.84 \%$ and reported that $3.8 \%$ in subjects more than 45 years (Brilliant et al. 1985). Other few population based studies were conducted in terai, 
and hilly regions of Nepal after 1981 (Pokharel, 1998; Sapkota et al. 2006; Serchan et al. 2010). These studies conducted in Lumbini Zone in 1998 and 2006 reported that the prevalence of blindness decreased to 1.7 from 2.5 in that area.

The major objective of this study is to know the agesex distribution of patients associated with visual impairment and blindness and to estimate the prevalence of visual impairment and blindness. Further, the paper is mostly focused on identifying the risk factors of visual impairment and blindness using hospital based data through the use of appropriate statistical model.

\section{MATERIALS AND METHODS}

The data for this study were collected retrospectively from the hospital records of the patients $(n=2000)$ which are relevant with this study as a secondary source from the Tilganga Institute of Ophthalmology (TIO), Kathmandu upon request. Since glaucoma is one of the largest causes of blindness and visual impairment, and this problem is found to be increasing with aging of the population, records of the patients' who has got treatments in the Glaucoma clinic of TIO Kathmandu of age 40 years and more were considered as the inclusion criteria.

\section{Statistical analysis}

Descriptive statistical measures such as mean, standard deviation (s.d.) for continuous variables and percentages for the categorical variables are presented. The relationship between internally scaled variables is assessed through the use of Pearson's correlation coefficient. The comparison of continuous covariates between two groups are assessed through the use of independent t- test, and three groups by using one way ANOVA followed by Bonferoni test as a post hoc analysis. Two independence of attributes are compared by using chi-square test or Fisher's exact test wherever applicable. There are two outcomes in this study. One is visual impairment and another is the blindness of the person. The nature of both the outcome variable is dichotomous- visual impairment versus normal and blindness versus normal. The appropriate regression for handling such data is the logistic regression model, mathematically expressed as follows.

Suppose that $\mathrm{k}$ independent observations $y_{1,} y_{2}, \ldots ., y_{k}$ and that the $\mathrm{i}^{\text {th }}$ observations can be treated as a realization of a random variable $Y_{i}$ assuming binomial distribution.

$Y_{i} \sim \mathrm{B}\left(\mathrm{n}_{i}, \pi_{i}\right)$ with binomial denominator $n_{i}$ and probability $\pi_{i}$.

Further, suppose that the logit of the underlying probability $\pi_{i}$ is a linear function of the predictors as: $\log i t\left(\pi_{i}\right)=\mathrm{x}_{i}^{\prime} \beta$

where $\mathrm{x}_{i}$ is a vector of covariates and $\beta$ is a vector of regression coefficients.

For detail about function for logistic regression and its application (Neter, 1996; Hosmer, 2000; Afifi, 2004; Kleinbaum, 2010). Odds ratio (OR) with $95 \%$ confidence interval (C.I.) for each considered covariate is reported. All the analysis was performed through the use of statistical software STATA 9.0 (Stata Corporation, Texas 77845, U.S.A.).

\section{RESULTS}

A total of 2000 patients were considered for the study with average age (mean \pm s.d.: $54.10 \pm 10.50$ ) years which constituted 1088 (54\%) females. On the basis of previous relevant studies and for further ease of analysis, the age of the patients has been categorized into four groups and found that more than one third (37\%) of the total patients under study are in the age group of $40-49$ years followed by $27 \%$ of the patients in the age group of 50 - 59 years old. In each age group (Fig. 1) females seem to be in higher side except in the age group 60-69 years.

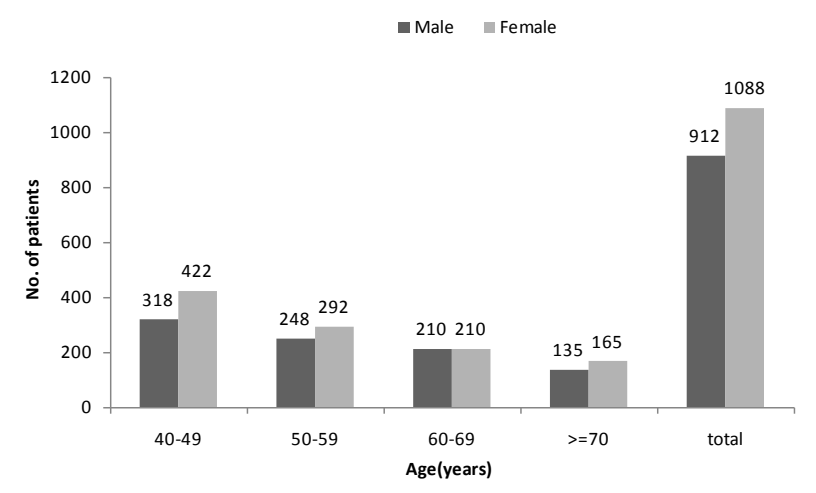

Fig. 1. Demographic distribution of patients

Among 2000 studied patients, 53\% were found illiterate and the proportion of females was found to be in higher side among literates and illiterates. However, there is not any significant association $(\mathrm{p}=0.170)$ between gender and the literacy status of the patients (table not shown).

Eye pressure, called intraocular pressure (IOP), is measured in millimeters of mercury $(\mathrm{mm} \mathrm{Hg})$. Normal eye pressure ranges from $10-21 \mathrm{~mm} \mathrm{Hg}$. The average IOP for left eye is mean \pm s.d.: $13.30 \pm 2.20$ and 13.34 \pm 2.30 for right eye indicating IOP more or less same for left and right eye. Further, there is not statistically significant average value of IOP gender wise in both left and right eye. The average value of IOP is found to be decreased as age increases (Table 1) in both the eyes. 
Table 1. Age wise distribution of IOP in study patients

\begin{tabular}{|c|c|c|c|c|c|}
\hline \multirow[b]{2}{*}{$\begin{array}{c}\text { IOP } \\
(\mathrm{mm} \mathrm{Hg})\end{array}$} & \multicolumn{4}{|c|}{ Age in years } & \multirow[b]{2}{*}{ p-value } \\
\hline & $\begin{array}{c}40-49 \\
(n=740) \\
\text { mean } \pm \text { s. d. }\end{array}$ & $\begin{array}{c}50-59 \\
(n=540) \\
\text { mean } \pm \text { s. d. }\end{array}$ & $\begin{aligned} & 60-69 \\
(n= & 420) \text { mean } \\
& \pm \text { s. d. }\end{aligned}$ & $\begin{array}{c}>=70 \\
(n=300) \text { mean } \pm \\
\text { s. } d .\end{array}$ & \\
\hline Right eye & $13.50 \pm 2.20$ & $13 . .34 \pm 2.30$ & $13.05 \pm 2.31$ & $12.80 \pm 2.50$ & $<0.001$ \\
\hline Left eye & $13.45 \pm 2.15$ & $13.33 \pm 2.21$ & $12.97 \pm 2.40$ & $12.61 \pm 2.30$ & $<0.001$ \\
\hline
\end{tabular}

It is found that there is significant difference of the average value of IOP across the four age groups in overall for both the eyes. The posthoc test result showed that the difference in average IOP is found significant between 40 - 49 age group versus 60 - 69 age group $(p<0.05)$ and between 40 - 49 age group versus 70 years or more age group $(\mathrm{p}<0.05)$ in both the cases. Notable point is that there is no significant difference of IOP between the age group of 50 - 59 years versus 60 - 69 years, between 40 49 years versus 50 - 59 years and between 60 - 69 years age group versus patients with age group 70 years and more. The central corneal thickness (CCT) nowadays has been found to be considered as one of the major measurement in the diagnosis of eye disease which is generally measured by $(\mu \mathrm{m})$. The normal range of CCT is $520(\mu \mathrm{m})-540(\mu \mathrm{m})$. However it varies between ethnic groups (La Rosa et al. 2001). The average CCT of studied subjects for left eye is mean \pm s.d.: $538.50 \pm 40.00$ and for right eye is $539.00 \pm 33.00$ indicating that there is slightly difference in average value of CCT between left eye and right eye.

There is significantly $(\mathrm{p}<0.05)$ higher average value of CCT in males as compared with those in females (Table2) for each left as well as right eye. The average CCT is found to be statistically significant in overall (Table3) for different age groups of patients in both the eyes.

Table 2. Gender wise distribution of CCT in study patients

\begin{tabular}{|c|c|c|c|c|}
\hline $\begin{array}{c}\mathbf{C C T} \\
(\boldsymbol{\mu m})\end{array}$ & $\begin{array}{c}\text { Male } \\
(\mathbf{n = 9 1 2}) \\
\mathbf{m e a n} \pm \mathbf{s .} \mathbf{d} .\end{array}$ & $\begin{array}{c}\text { Female } \\
(\mathbf{n = 1 0 8 8}) \\
\text { mean } \pm \mathbf{s . d} .\end{array}$ & Mean difference & p-value \\
\hline Right eye & $540.80 \pm 33.91$ & $537.80 \pm 32.91$ & 3.00 & 0.035 \\
\hline Left eye & $540.30 \pm 42.50$ & $537.00 \pm 37.6$ & 3.30 & 0.040 \\
\hline
\end{tabular}

Table 3. Age wise distribution of CCT in study patients

\begin{tabular}{|c|c|c|c|c|c|}
\hline \multirow[b]{2}{*}{$\begin{array}{l}\text { CCT } \\
(\mu \mathrm{m})\end{array}$} & \multicolumn{4}{|c|}{ Age in years } & \multirow[b]{2}{*}{ p-value } \\
\hline & $\begin{array}{c}40-49 \\
(n=740) \\
\text { mean } \pm \text { s. d. }\end{array}$ & $\begin{array}{c}50-59 \\
(n=540) \\
\text { mean } \pm \text { s. d. }\end{array}$ & $\begin{array}{c}60-69 \\
(n=420) \\
\text { mean } \pm \text { s. d. }\end{array}$ & $\begin{array}{c}>=70 \\
(n=300) \\
\text { mean } \pm \text { s. d. }\end{array}$ & \\
\hline Right eye & $541.01 \pm 32.72$ & $540.02 \pm 33.54$ & $533.72 \pm 34.05$ & $534.44 \pm 34.33$ & 0.001 \\
\hline Left eye & $540.10 \pm 40.61$ & $539.90 \pm 33.53$ & $532.61 \pm 46.58$ & $533.53 \pm 43.68$ & 0.005 \\
\hline
\end{tabular}

However, the posthoc analysis suggest that the average CCT is significantly $(p<0.05)$ different between the age group of 40 - 49 versus 60 - 69 and 50 - 59 versus 60- 69 years age group of patients for both the eyes. But for other possible combinations of age groups under consideration, CCT has not turned on statistically significant.

There is positive correlation $(r=0.23, p<0.001)$ between IOP and CCT of right eyes whereas age is negatively associated with IOP $(-0.096, \mathrm{p}<0.001)$ and CCT $(-$ $0.085, \mathrm{p}<0.001)$.

There were altogether $710(36 \%)$ subjects under study were having visually impaired (low vision) and very few 29(1.45\%) were having blindness among the study subjects. There is significant $(\mathrm{p}=0.026)$ association between the gender and the characteristic of the vision (normal vision, visual impairment and blindness) indicating that the proportion of having visual impairment and blindness each is found higher in the females as compared to males.

Age is found to be statistically significant $(p<0.001)$ with the distribution of vision. The prevalence of having visually impaired is increasing as age increases in both 
the scenario-at better eye before correction and after correction. The prevalence of having visual impairment in the age group of 40 - 49 years is $13.11 \%, 95 \%$ C.I.: $10.76 \%-15.75 \%)$ and it reaches to very high $(89.00 \%$, 95\% C.I.: $84.89 \%-92.30 \%)$ in the age group of patients having age 70 years or more(Fig. 2) clearly indicating that age is one of the major risk factor of having visual impairment. The similar scenario can also be observed for the blindness but not exactly the similar trend of prevalence as that of blindness as age increases.

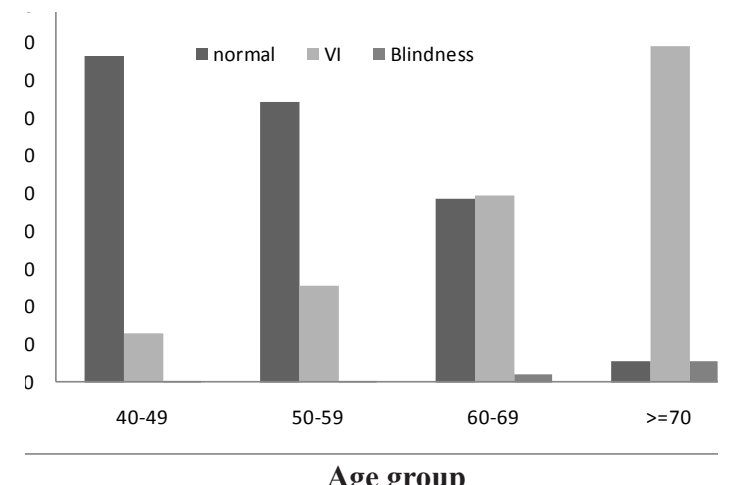

Age group
However, the distribution of vision is not significantly associated $(p=0.608)$ with literacy status of the patients in both the scenario. Noteworthy point is that there is considerable improvement in the vision after correction of the eyes as compared with those of before correction of refractive errors (table not shown).

As the number of blind people is found to be very small in number (29 at presentation and 17 after correction out of 2000 subjects ), for carrying out the logistic regression analysis, it is decided to merge blind persons with low vision and again called it as visual impairment by considering the clinicians' opinions. Now the outcome variable is treated as visual impairment versus normal groups. The logistic regression (Table 4) shows that only age and gender has come out to be the significant risk factors for the development of visual impairment in better eye at presentation. Results shows that the odds of having visually impaired in better eye at presentation in the age group 60-69 years is almost five folds (OR: 4.92, 95\% C.I: 3.81- 6.36) times higher as compared with those patients in age group $40-49$ years.

Fig. 2. Age wise prevalence of VI and blindness (better eye)

Table 4. Risk factors of visual impairment in better eye at presentation: Results of univariate and multivariate logistic regression

\begin{tabular}{|l|l|l|l|l|}
\hline \multicolumn{2}{|c|}{ Univariate } & \multicolumn{3}{c|}{ Multivariate } \\
\hline Characteristic & OR(95\% C.I.) & p-value & OR(95\% C.I.) & p-value \\
\hline Age(years) & & & & \\
$40-49$ & 1.00 & - & 1.00 & \\
$50-59$ & $2.04(1.56,2.67)$ & $<0.001$ & $2.06(1.56, \quad 2.70)$ & $<0.001$ \\
$60-69$ & $4.82(3.73,6.22)$ & $<0.001$ & $4.92(3.81,6.36)$ & $<0.001$ \\
$\geq 70$ & $13.43(10.35,17.43)$ & $<0.001$ & $13.62(10.49,17.69)$ & $<0.001$ \\
\hline Gender & 1.00 & & & \\
Male & $1.20(1.02 \quad 1.41)$ & 0.025 & 1.00 & \\
Female & & & \\
\end{tabular}

While assessing the risk factors of visual impairment in better eye after correction, only age has come out to be the significant risk factor (Table 5). Neither gender nor literacy is found statistically significant.

The odd of having visual impairment is 1.92 times highly associated in 50 - 59 age group of people as compared with those of 40 - 49 age group of people.

The response curve (Fig. 3) for the logistic regression model as derived from the results of Table 5 clearly shows that the nature of the curve is rising indicating that the likelihood of the development of visual impairment increases exponentially as age increases.
Table 5. Risk factors of visual impairment in better eye after correction: Results of logistic regression

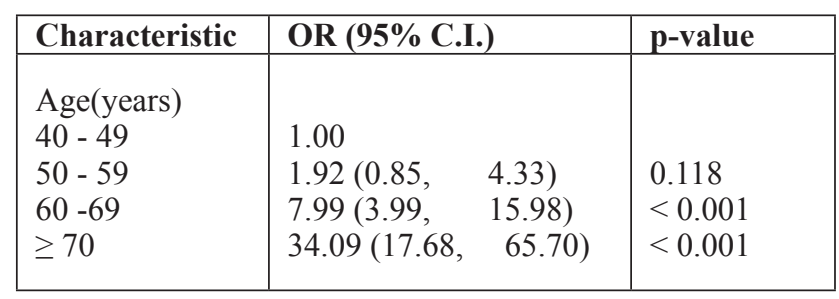

Hence the probability of development of visual impairment is 0.19 (approximately) in the age group of 70 years and above whereas it was 0.007 in the age group of $40-49$ years. 


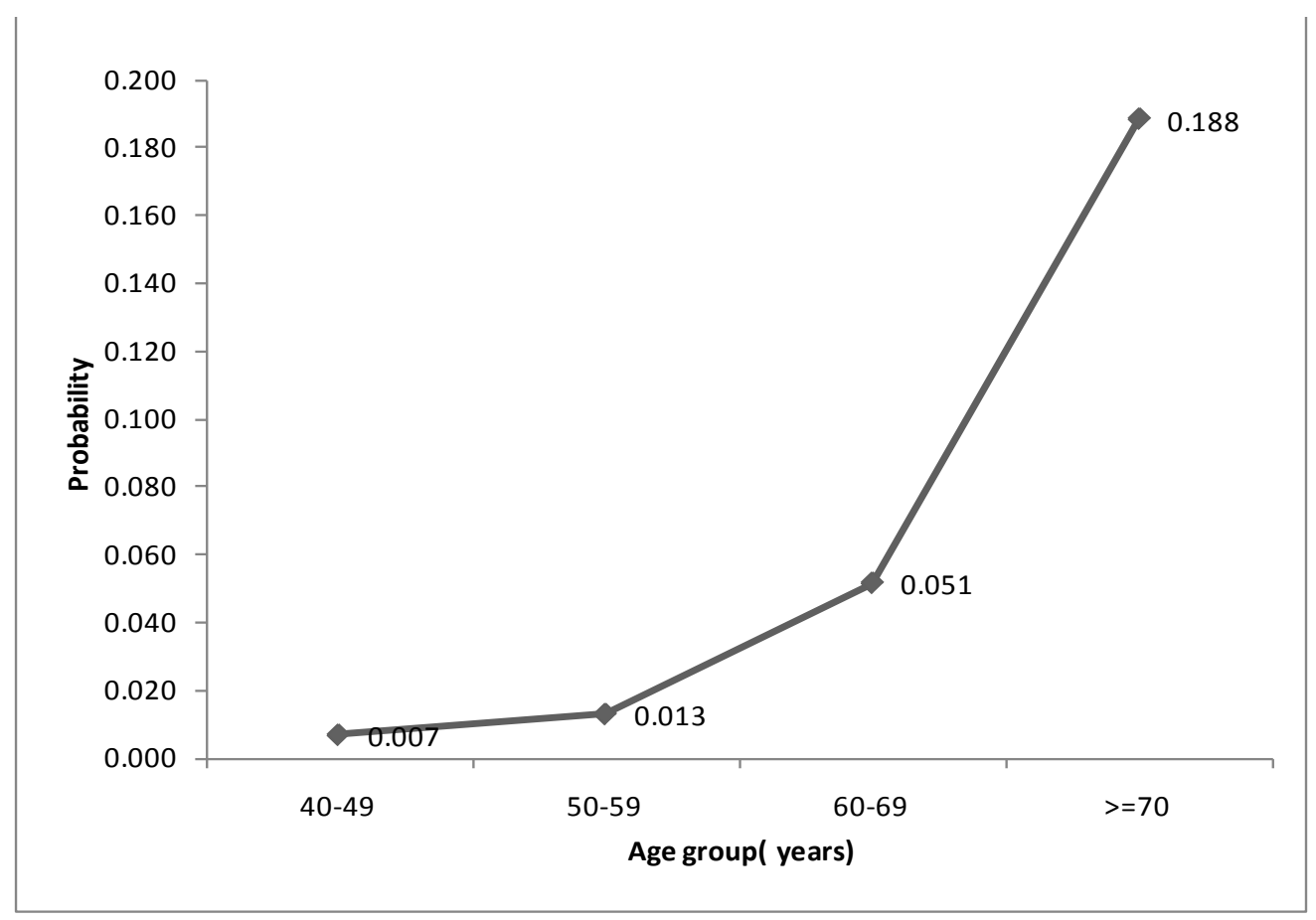

Fig. 3. Response curve: probability of development of visual impairment against age

\section{DISCUSSION AND CONCLUSIONS}

Female predominance is found in the study subjects consisting of 1088 (54\%) females. More than one third $(37 \%)$ of the total patients under study are in the age group of 40 - 49 years followed by $27 \%$ of the patients in the age group of $50-59$ years old. Females are also found in higher side in each age group except in the age group of $60-69$ years. In the age group of 60-69 years, both males and females remain the same. Literacy status is not statistically significant with gender $(p=0.170)$.

We could not find significant association between gender and IOP both in left and right eyes. There is mix information reported from the other studies in this respect. Some studies had been reported that there is no significant difference of IOP gender wise and some had showed significant difference (Lekskul et al. 2005; Nomura, 2002; Wong, 2009). However we could not find why this difference has been observed. The average value of CCT has been observed to be significantly higher in males as compared with females. The clinical relevance of such results also could not be found.

There is no significant difference between the average value of the intra ocular pressure (IOP) in left eye and in right eye and no significant difference of average central corneal thickness (CCT) between left eye and right eye. Therefore, IOP and CCT of only right eye have been considered to see the relationship between them. Age is associated negatively with IOP and CCT. Not all other studies are in the similar direction in this respect (Lekskul et al. 2005; Nomura, 2002; Wong, 2009).

It is decided to merge blind persons with the persons having low vision and consequently the outcome variable, especially for logistic regression, is treated as visual impairment versus normal group. There are two reasons behind applying this approach -(i) we have encountered the problem of convergence of logistic regression as there are very few subjects having blindness in different subgroups, (ii) the another problem we faced is that the odds ratios are inflated because of small number of blindness subjects distributing in different subgroups. The odds ratio for the age group of 70 years and above seems to be highly inflated (OR: $34.09,95 \%$ CI: 17.68 65.70 ). It might be because of small number of visually impaired persons in this group as compared with normal subjects.

The prevalence of visual impairment and blindness increases as age increases in both scenarios- at presentation and after presentation. The risk of developing visual impairment also increases exponentially with the increase in age in both the considerations. The risk of developing visual impairment in females is 1.3 times higher as compared with males in the first consideration whereas in the later consideration gender does not show any difference in the development of visual impairment. Similarly, literacy also does not show any considerable association with visual impairment and blindness. To be concluded, everyone after attaining the age of 40 years of 
age needs to consult ophthalmologists to be in the safer side.

However, the generalization of the findings of this study may not be logical as it is based only on the secondary data taken from only one hospital of Kathmandu valley. In this respect, this study can be considered as an exploratory study. Keeping in view of this reality, one can plan further study with sufficiently large sample sized community based survey to generalize the findings even for Nepalese context.

\section{ACKNOWLEDGEMENTS}

Authors would like to acknowledge the University Grants Commission (UGC) Nepal for the financial support provided under the scheme of Faculty Research Grants to carry out this study. We are also indebted to Tilganga Institute of Ophthalmology (TIO) Kathmandu for providing the secondary data for this study. We would also like to thank referees for their candid comments.

\section{REFERENCES}

Afifi, A., Virginia, A. C., and Susanne, M. 2004. Computer Aided Multivariate Analysis. New York, Chapman \& Hall/CRC.

All countries.(n.d.). Global estimate of visual impairment, by WHO region (millions), 2002. Retrieved June 11, 2012, from http://www.allcountries.org/health/ magnitude and causes of visual impairment.html

Blindness. (n.d.). In Blindness wiki. Retrieved June 11, 2010, from http: //www. en.wikipedia.org/wiki/

Brilliant, L. B., Pokhrel, R. P., Grasset, N. C., Lepkowski, J. M., Kolstad, A., Hawks, W., Pararajasegaram, R., Brilliant, G. E., Gilbert, S., Shrestha, S. R., \& Kuo J. 1985. Epidemiology of blindness in Nepal. Bulletin of World Health Organ 63: 375-386.

Hosmer D.W., and Lemeshow, S. 2000. Applied Logistic Regression. New York, Wiley.

Kleinbaum D.G. \& Klein M. 2010. Logistic Regression: A Self Learning Text. New York: Springer Publications.

La Rosa, F.A., Gross R.L., and Orengo-Nania, S. 2001. Central corneal thickness of caucassians and Africans in glaucomatous and non glaucomatous populations. Arch Opthalmology 119: 23-27.

Lekskul, M., Aimpun, P., Nawanopparatskul, B., Bumrungsawat. S., Trakulmungkijkarn, T., Charoenvanichvisit, J., Herunpattarawong, T., ... and Sudprasert, T. 2005. The correlations between central corneal thickness and age, gender, intraocular pressure and refractive error of aged 12-60 years old in rural Thai community. $J$ Med Assoc Thai 3: 175-179.
Neter, J., Kutner, M.H., Nachtsheim, C.J., and Wasserman, W. 1996. Applied Linear Statistical Models. U.S.A.: MCGraw-Hill.

Nomura, H., Ando, F., Niino, N., Shimokata, H., and Miyake, Y. 2002. The relationship between age and intraocular pressure in a Japanese population: the influence of central corneal thickness. Curr Eye Res 2: 81-85.

Pascolini, D., Mariotti, S.P., Pokharel, G.P., Pararajasegaram, R., Etya'ale, D., Négrel, A.D., and Resnikoff, S. 2004. 2002 Global update of available data on visual impairment: a compilation of population-based prevalence studies. Ophthalmic Epidemiol 11: 67-115.

Pokharel, G.P., Regmi, G., Shrestha, S.K., Negrel, A.D., and Ellwein, L. B. 1998. Prevalence of blindness and cataract surgery in Nepal. Br J Ophthalmol 82: 600-605.

Sapkota, Y.D., Pokharel, G.P., Nirmalan, P.K., Dulal, S., Maharjan, I.M., and Prakash, K. 2006. Prevalence of blindness and cataract surgery in Gandaki Zone, Nepal. Br J Ophthalmol 90: 411- 416.

Sherchan, A., Kandel, R.P., Sharma, M.K., Sapkota, Y.D., Aghajanian, J., and Bassett, K. L. 2010. Blindness prevalence and cataract surgical coverage in Lumbini zone and Chitwan district of Nepal. $B r J$ Ophthalmol 94: 161-166.

WHO 1992. World Health Organization Report on International Statistical Classification of Diseases and Related Health Problems (10 $0^{\text {th }}$ revised edition). Retrieved from http://www.who.int/ classifications/icd/en/

WHO 2004. World Health Organization Fact sheet on Magnitude and cause of visual impairment. No. 282. Retrived from http://whqlibdoc.who.int/fact sheet/2004/FS_282.pdf

Wong, T.T., Wong, T.Y., Foster, P.J., Crowston, J.G., Fong, C.W., and Aung T. 2009. The relationship of intraocular pressure with age, systolic blood pressure, and central corneal thickness in an Asian population. Invest Ophthalmol Vis Sci. 9: 40975002. 